\title{
Evaluating economic relationships of stapled and traditional Australian REITs
}

\author{
$\underline{\text { J. Yong }}{ }^{\text {a }}$, D.E. Allen ${ }^{\text {a }}$ and L.K. Lim ${ }^{\text {a }}$ \\ ${ }^{a}$ School of Accounting, Finance and Economics, Edith Cowan University, Western Australia. \\ Email: jaime.yong@ecu.edu.au
}

\begin{abstract}
The number of Australian Real Estate Investment Trusts (AREITs) trading as stapled securities has grown significantly in the past ten years. Though this type of trust structure improves the income growth to investors, stapled AREITs are riskier relative to traditional AREITs that act primarily as holding companies of property assets. Academic literature on REIT characteristics has found that these assets have become less integrated with bonds and more with stocks. An increasingly mature AREIT market implies that prices of these assets have become more integrated with values of the underlying direct property investments.
\end{abstract}

This study employs quarterly prices over 30 years from 1980 to 2010, and the sample includes 71 AREITs used to construct separate value-weighted indices for stapled and traditional trusts. Using cointegration analysis, this paper aims to examine the relationships of traditional and stapled AREITs with expected and unexpected growth in real estate prices, stocks, bonds, as well as expected and unexpected inflation. Because inflation is driven by changes to real economic activity, and appraisal based direct property indices are prone to a smoothing bias, we also use a set of macroeconomic factors to represent demand for real estate and assess if these have meaningful relationships with traditional and stapled AREITs. These are industrial production and eight employment indices from the construction, entertainment related services, finance and insurance services, public administration and safety, manufacturing, rental and property services, utilities and, wholesale and retail trade sectors. Estimations were conducted with sample periods including and excluding the GFC.

Our results show that there is no long-run relationship between AREITs and expected capital growth of retail properties and unexpected capital growth of industrial properties. Stapled AREITs do not exhibit any relationship with unexpected capital growth of office properties. These results only apply when the sample period excludes the GFC. The significance of the error correction term when direct property was assumed as the dependent variable provides support that AREIT prices are significant in explaining expected and unexpected capital growth of direct properties. We also find that in the long-run, AREITs are good hedges against expected inflation, but only stapled AREITs can hedge against unexpected inflation. Estimates of the vector error correction model also indicate that traditional AREITs exhibit short-run adjustments to both stock and bond market factors, whereas stapled AREITs only adjust to stocks. When assessed against a set of macroeconomic variables representing primary demand factors for real estate, we find that traditional AREITs display a significant relationship with industrial production and employment in the construction sector. In the set of secondary demand factors for real estate, we find a persistent long-run relationship for traditional AREITs in periods including and excluding the GFC. Overall, our findings suggest that stapled AREITs do not display a long-run relationship with macroeconomic factors that drive real estate prices, providing further support that stapled AREITs are more like stocks and are poor substitutes for direct property investments.

Keywords: Real estate investment trusts, cointegration, inflation, stocks, economic variables. 


\section{INTRODUCTION}

Since 2000, and increasing number of Australian Real Estate Investment Trusts (AREITs henceforth) have adopted a stapled structure ${ }^{1}$. Traditional AREITs are externally managed, and function as entities holding income-producing real estate. A minimum of 90 percent of trust income is distributed to unit holders while an external manager is appointed to manage underlying property investments. Considered investment vehicles that offer relatively stable cash flows similar to direct property investments, they also have the added benefit of liquidity since units trade on a stock exchange. In contrast, stapled AREITs entitle security holders with units in the trust itself and shares in the property management or development company. They have a more active investment strategy, where assets are chosen based on growth potential and income streams are expanded to operations in property management and development. The implications of the difference between traditional and stapled AREITs have not been adequately studied in existing literature.

Because AREITs hold an underlying portfolio of direct property, it is expected that property prices have a driving influence on AREITs. However, Gyourko and Keim (1992), Myer and Webb (1993) and Clayton and MacKinnon (2001) find that REITs and property returns lack significant correlations due to the appraisal smoothing bias of the direct property index, but contemporaneous and past values of REITs explain direct property. This provides evidence that the REIT market is more informationally efficient than the direct property market, and REITs provide a lead for the prices of appraised real estate. In this paper, we attempt to examine if traditional and stapled AREITs display different relationships to direct property investments. We separate direct property prices into expected (appraisal-based) and unexpected components, which will allow us to detect if unexpected changes to property prices have an impact on AREITs.

There is also a general consensus that property is a good hedge against inflation but in comparison, it has been documented that stocks and inflation have a negative relationship. On one hand, the stock-like characteristics of REITs would suggest they are poor inflation hedges (Liu et al., 1997), whereas their real estate characteristics would suggest otherwise. Glascock et al. (2002) provide evidence that nominal, expected and unexpected inflation have negative impacts on REITs, supporting the widely accepted conclusions that REITs behave more like stocks and are perverse inflation hedges, and REIT behaviour deviate from real estate. This paper also aims to examine if traditional and stapled AREITs are able to provide an adequate hedge against expected and unexpected inflation.

REITs have also been found to be integrated with stocks and bonds (Karolyi and Sanders, 1998; Ling and Naranjo, 1999; Glascock et al., 2002). However, these studies have found that REIT characteristics have more recently become more stock-like and less bond-like. Evidence from Australian studies have found that short-run correlations of stapled AREITs with stocks have increased since 1993, and this is because stapled AREITs are operationally riskier (Newell and Tan, 2005; Newell and Peng, 2009). Our paper will consider if traditional AREITs are more like bonds and if stapled AREITs are more like stocks.

Property prices are also likely to be influenced by other demand and supply side factors that can be easily measured at the macro level. Chan et al. (1990) and Karolyi and Sanders (1998) find that industrial production is significant in explaining REIT returns. Liang and McIntosh (1998) and West and Worthington (2006) suggest that employment growth in various industries signal higher property prices as they are proxies for increased demand for commercial space. In our paper, we will use industrial production and a set of primary and secondary demand factors for real estate based on employment data by sector, and assess if these economic variables have value in describing the underlying prices for traditional and stapled AREITs. The remainder of the paper are structured as follows. Section 2 outlines the data employed and methodology used namely, the Johanssen (1991) test for cointegration. Section 3 presents the results of our three main research questions, and Section 4 concludes.

\section{DATA AND METHODOLOGY}

The full sample period spans from 1980 to 2010, whereas the sample period which excludes the GFC spans from 1980 to June 2008. Data of 71 AREITs was sourced from Datastream. Three indices representing the overall AREIT sector $(A L L)$, traditional $(T T)$ and stapled $(S T)$ trusts were constructed to assess if there are differences between traditional and stapled AREITs with the set of explanatory variables. ${ }^{2}$ The S\&P/ASX200

\footnotetext{
${ }^{1}$ Stapled AREITs have grown from 15 percent to 61 percent of total listed AREITs on the Australian Stock Exchange from 2000 till 2011.

${ }^{2} A L L, T T$ and ST were constructed using the Standard and Poor's market capitalisation index method. The index divisor is revised in the month of additions into the relevant category due to new listings, while deletions are made in the month of suspension, delisting or in the event of the trust switching to a stapled structure. By adjusting the divisor during such events, the sudden increases or decreases in total market capitalisation of the indices are minimised, and the distortions to the index due to non-market related events are reduced.
} 
were used to represent general equities (STOCK) and yields of 10-year Commonwealth government bonds from the Reserve Bank of Australia were used to derive the bond price index (BOND). To represent demand for property assets, quarterly data of industrial production (INDP) and employment indices from various economic sectors were sourced from the Australian Bureau of Statistics (ABS). The eight employment indices are: construction $(C O N)$, entertainment related services $(E R S)$, finance and insurance services $(F I N)$, public administration and safety $(G O V)$, manufacturing $(M A N)$, rental and property services $(P B S)$, utilities (UTIL), and wholesale and retail trade (WRT).

The Consumer Price Index was sourced from the ABS and this was decomposed into expected $(E I N)$ and unexpected (UIN) inflationary components. EIN was estimated using an $\mathrm{AR}(2)$ model of the realised inflation rate, and the residuals were saved as UIN. From these, expected CPI (ECPI) and unexpected CPI (UCPI) indices were reconstructed. Capital growth indices for direct property investments published by Mercer/IPD were also sourced from Datastream. To address the smoothing issues of appraised property prices, these were also decomposed into expected and unexpected capital growth components using the same methodology for inflation above. As a result, eight indices representing expected and unexpected capital growth for all properties, industrial, office and retail properties were derived and denoted as: APRECG, APRUCG, INDECG, INDUCG, OFFECG, OFFUCG, RETECG and RETUCG.

If two non-stationary time series are cointegrated, they will both be stationary in their first differences. The presence of cointegration implies that there is a linear long-run equilibrium relationship between the price levels of two variables. The Johansen (1991) procedure to test for cointegration is adopted in this study because it allows us to test for the presence of multiple cointegrating vectors assuming all variables are endogeneous to the system. A joint framework is also available to estimate and test the cointegrating equations within the vector error correction models (VECM) and there are appropriate statistics to test the hypothesis for the number of cointegrating equations.

Suppose that a $\operatorname{VAR}(k)$ model has an $n \times 1$ vector of I(1) time series prices $P_{t}$ :

$P_{t}=A_{1} P_{t-1}+\ldots+A_{k} P_{t-k}+\varepsilon_{t}$

$P_{t-k}$ are assumed to be predetermined, $A_{i}$ are $n \times n$ matrices of parameters and $\varepsilon_{t}$ is an $n \times 1$ i.i.d. Gaussian error vector. The maximum number of lag lengths $k$ necessary to process the white noise in the error term can be selected based on the highest values of the Akaike (AIC), Schwarz (SC) and Hannan-Quinn (HQ) information criteria. The VECM in (2) can be obtained by rewriting equation (1) in terms of first differences and including a constant term, $\delta$ :

$$
\Delta P_{t}=\delta+\Gamma_{1} \Delta P_{t-1}+\ldots+\Gamma_{k-1} \Delta P_{t-k+1}+\Pi P_{t-1}+\varepsilon_{t}
$$

The term $\Delta P_{t}$ is the vector of price changes in period $t, \Gamma$ is the vector of short-run dynamics, and $\Pi$ is the long-run impact matrix, which has a reduced rank in the presence of cointegration. The rank of the $\Pi$ matrix determines the number of linear combinations of $P_{t}$. If the rank is $r$ and $r<n$, so that $r$ linear combinations of nonstationary variables are $\mathrm{I}(0)$, then it can be said that $r$ cointegrating vectors exist. Since $\Pi$ does not have a full rank, two $n \times r$ matrices, $\alpha$ and $\beta$ can be factored into the system so that $\Pi=\alpha \beta^{\prime}$ and equation (2) can be rewritten as:

$$
\Delta P_{t}=\delta+\sum_{i=1}^{k-1} \Gamma_{i} \Delta P_{t-i}+\alpha \beta^{\prime} P_{t-1}+\varepsilon_{t}
$$

In equation (3), the $r$ columns of $\beta$ are the cointegrating vectors and represent the linear independent combinations of $P_{t}$ that are stationary. $\alpha$ is the matrix of error correction terms showing the impact of $r$ cointegrated vectors on $\Delta P_{t}$. The $i$ th row of $\alpha$ represents the strength and direction of the adjustment process. Johansen $(1988,1991)$ also developed maximum likelihood procedures for testing the existence of cointegration within a system of equations. Eigenvalues are calculated to determine the rank of the estimated long-run impact matrix. Trace and maximum eigenvalue tests are used to evaluate the number of significantly non-zero eigenvalues to show the rank of the long-run impact matrix.

The first group of tests explores if there is a long-run equilibrium relationship between AREITs and expected and unexpected capital growth of direct property investments. The estimates of the VECM should indicate whether or not changes in direct property prices contain information in the pricing of AREITs, or vice versa. The second group of tests analyses if AREITs are cointegrated with financial assets, namely stocks and bonds, taking into account expected and unexpected inflation. Also of particular interest, is if stapled AREITs behave more like stocks, while traditional AREITs behave more like bonds. Lastly, the third group of tests aim to explore if there is value in using indicators of real economic activity in the pricing of AREITs. The estimates should provide information of whether demand factors from various sectors of the economy have 
different pricing impacts on stapled and traditional AREITs. Each test is conducted using a sample period which includes and excludes the GFC, to assess if this event has any impact on the long-run relationships and short-run adjustment dynamics.

\section{RESULTS}

Table 1 presents the results of cointegration tests for $A L L, T T$ and $S T$ with expected and unexpected prices of direct property. For the sample period which includes the GFC, there appears to be no long-run relationship between AREITs and direct property. However, when the GFC was excluded from the study period, the trace and maximum-eigenvalue tests detect the presence of one cointegrating vector. There were some exceptions: no relation was found for $T T$ and $S T$ with expected capital growth of retail properties, AREITs were not found to be cointegrated with unexpected capital growth of industrial properties, and no relation was found for $S T$ with unexpected capital growth of office properties.

The long-run equilibrium coefficients are not detailed here but they all provide similar findings. When $A L L$, $T T$ and $S T$ were set as the dependent variable in the VECM, the long-run equilibrium equation not found to be statistically significant. But when the direct property indices were set as the dependent variable, all the error correction terms were found to be negative and statistically significant at the $1 \%$ level. This provides evidence that expected and unexpected prices of direct property correct to the long-run disparity with the prices of AREITs. This is consistent with the suggestion of Clayton and MacKinnon (2001) that the AREIT sector is mature and contains information in the pricing of direct property investments. Examples of the longrun equilibrium equations were found to be: $A P R E C G=0.0356 T T-1.1526$ Trend +163.8613 , and RETUCG $=0.0017 S T-0.0664$ Trend +103.1449 , which indicate that an increase in the price of $T T$ and $S T$ is met by an increase in expected capital growth of all properties and unexpected capital growth of retail properties respectively.

Table 1: Cointegration tests for AREITs and direct property.

Tests for appropriate lag length indicate a maximum of 2 preceding quarters is suitable. For the null hypothesis of no cointegrating vectors $(r=0)$, the 5 percent critical value for the trace test is 25.8721 and 19.3870 for the maximum eigenvalues. For the null hypothesis of at most one cointegrating vector $(r \leq 1)$, the 5 percent critical value for the trace and maximum eigenvalue statistic is 12.5179. * denotes a rejection of the null hypothesis at the $5 \%$ level of significance.

\begin{tabular}{|c|c|c|c|c|c|c|}
\hline \multirow[b]{3}{*}{$\begin{array}{l}\text { Hypothesised } \\
\text { no. of } r \text { vectors }\end{array}$} & \multicolumn{3}{|c|}{ Includes GFC $(n=97)$} & \multicolumn{3}{|c|}{ Excludes GFC $(n=87)$} \\
\hline & \multirow[b]{2}{*}{ Trace Statistic } & $r=0$ & \multirow{2}{*}{$\begin{array}{l}r \leq 1 \\
\text { Trace \& Max- } \\
\text { Eigen. Statistic }\end{array}$} & \multirow[b]{2}{*}{ Trace Statistic } & $r=0$ & \multirow{2}{*}{$\begin{array}{l}r \leq 1 \\
\text { Trace \& Max- } \\
\text { Eigen. Statistic }\end{array}$} \\
\hline & & $\begin{array}{l}\text { Max-Eigen. } \\
\text { Statistic }\end{array}$ & & & $\begin{array}{l}\text { Max-Eigen. } \\
\text { Statistic }\end{array}$ & \\
\hline $\boldsymbol{A L L}$ and... & & & & & & \\
\hline$A P R E C G$ & 11.6089 & 7.6311 & 3.9777 & $29.5521 *$ & $23.2913 *$ & 6.2608 \\
\hline$I N D E C G$ & 17.0963 & 12.4758 & 4.6205 & $32.2294 *$ & $25.8017 *$ & 6.4277 \\
\hline OFFECG & 12.5661 & 9.1464 & 3.4198 & $30.2699 *$ & $24.5961^{*}$ & 5.6737 \\
\hline RETECG & 7.1977 & 6.2927 & 0.9051 & $26.2047 *$ & 15.4666 & 10.7382 \\
\hline$A P R U C G$ & 14.3214 & 10.2237 & 4.0976 & $30.8620 *$ & $23.1145^{*}$ & 7.7475 \\
\hline$I N D U C G$ & 11.4318 & 7.1276 & 4.3042 & 19.4265 & 14.3578 & 5.0587 \\
\hline OFFUCG & 14.6382 & 10.7091 & 3.9292 & $28.9801 *$ & $20.9325^{*}$ & 8.0476 \\
\hline RETUCG & 16.6422 & 10.7975 & 5.8447 & $26.5013 *$ & $19.5635^{*}$ & 6.9377 \\
\hline \multicolumn{7}{|l|}{$\boldsymbol{T T}$ and... } \\
\hline APRECG & 10.6211 & 8.5195 & 2.1015 & $30.5036^{*}$ & $24.2367^{*}$ & 6.2669 \\
\hline INDECG & 14.1348 & 10.7505 & 3.3843 & $32.2792 *$ & $25.6016^{*}$ & 6.6776 \\
\hline OFFECG & 10.9831 & 9.1778 & 1.8053 & $31.4298 *$ & $25.6217^{*}$ & 5.8082 \\
\hline RETECG & 18.4654 & 12.4754 & 5.9899 & 24.5938 & 13.4982 & 11.0956 \\
\hline$A P R U C G$ & 11.7101 & 10.0074 & 1.7026 & $32.4541 *$ & $24.7456^{*}$ & 7.7085 \\
\hline$I N D U C G$ & 8.7716 & 6.3493 & 2.4223 & 21.6439 & 16.9818 & 4.6621 \\
\hline OFFUCG & 12.2729 & 10.4816 & 1.7914 & $30.4775^{*}$ & $22.4382 *$ & 8.0394 \\
\hline RETUCG & 12.8389 & 10.1281 & 2.7108 & $28.9241 *$ & $21.1335^{*}$ & 7.7907 \\
\hline \multicolumn{7}{|l|}{$\boldsymbol{S} \boldsymbol{T}$ and... } \\
\hline APRECG & 10.2957 & 8.9140 & 1.3817 & $29.1523 *$ & $25.6877 *$ & 3.4646 \\
\hline$I N D E C G$ & 12.3115 & 10.5880 & 1.7727 & $32.2172 *$ & $28.6783^{*}$ & 3.5389 \\
\hline OFFECG & 10.7247 & 9.3276 & 1.3971 & $29.6277^{*}$ & $26.3703^{*}$ & 3.2574 \\
\hline RETECG & 18.7514 & 13.8982 & 4.8532 & 21.8726 & 14.0253 & 7.8474 \\
\hline$A P R U C G$ & 12.7973 & 11.5837 & 1.2135 & $26.8399 *$ & $21.1358^{*}$ & 5.7040 \\
\hline$I N D U C G$ & 8.4663 & 6.9691 & 1.4972 & 13.4359 & 9.3643 & 4.0717 \\
\hline OFFUCG & 12.8704 & 11.5697 & 1.3007 & 24.4264 & 19.2309 & 5.1955 \\
\hline RETUCG & 13.8422 & 12.2024 & 1.6398 & $28.2751 *$ & $19.9912 *$ & 8.2839 \\
\hline
\end{tabular}

Next the long-run relationships between AREITs, expected CPI, unexpected CPI, stocks and bonds are assessed, where the results are presented in Table 2. In the sample period that includes the GFC, the tests detect two cointegrating vectors between $T T$ and $S T$ with ECPI, UCPI, STOCK and BOND, and only one vector in the system involving $A L L$. When the sample period excludes the GFC, three cointegrating vectors were detected in the systems of $A L L$ and $T T$ whereas only two were detected in the system for $S T$. For 
brevity, the long-run cointegrating coefficients are not reported here. However, AREITs were found to have a positive relationship with stocks and a negative relationship with bonds. Also, when expected CPI increased, prices of AREITs rose. But when unexpected CPI increased, ALL and TT decreased whereas ST increased. These findings are similar to Glascock et al. (2002) and Newell and Tan (2005), that AREITs behave more like stocks than bonds. Additionally, AREITs can act as good hedges against expected inflation. However, only stapled AREITs can hedge against unexpected inflation, as this was not the case for traditional AREITs.

Table 2: Cointegration tests for AREITs, CPI and financial assets.

Tests for the appropriate lag length indicate a maximum of 2 preceding quarters is suitable. ${ }^{*}$ denotes a rejection of the null hypothesis at the $5 \%$ level of significance.

\begin{tabular}{|c|c|c|c|c|c|c|c|}
\hline \multirow{2}{*}{$\begin{array}{l}\text { Hypothesised no. } \\
\text { of } r \text { vectors }\end{array}$} & \multirow{2}{*}{$\begin{array}{l}5 \text { percent } \\
\text { critical value }\end{array}$} & \multicolumn{3}{|c|}{ Includes GFC $(\mathrm{n}=123)$} & \multicolumn{3}{|c|}{ Excludes GFC $(n=112)$} \\
\hline & & $A L L$ & $T T$ & $S T$ & $A L L$ & $T T$ & $S T$ \\
\hline \multicolumn{8}{|l|}{ Trace test } \\
\hline$r \leq 1$ & 47.8561 & 45.0219 & $51.4015^{*}$ & 46.8561 & $61.4959 *$ & $62.5686^{*}$ & $56.5770^{*}$ \\
\hline$r \leq 2$ & 29.7971 & 22.0321 & 24.0007 & 15.8138 & $35.0005^{*}$ & $34.8631 *$ & 26.1882 \\
\hline$r \leq 3$ & 15.4947 & 7.4499 & 7.0668 & 4.8083 & 11.3927 & 10.7031 & 8.4058 \\
\hline \multicolumn{8}{|l|}{ Max.-Eigen test } \\
\hline$r=0$ & 33.8768 & $84.5421 *$ & $81.4262 *$ & $69.7051 *$ & $77.9348^{*}$ & $84.0251 *$ & $66.7942 *$ \\
\hline$r \leq 1$ & 27.5843 & 22.9897 & $27.9108^{*}$ & $30.9066^{*}$ & $28.4953 *$ & $27.7054 *$ & $30.3888^{*}$ \\
\hline$r \leq 2$ & 21.1316 & 14.5822 & 16.9338 & 11.0055 & $23.6078^{*}$ & $24.1601 *$ & 17.7824 \\
\hline$r \leq 3$ & 14.2646 & 6.3451 & 6.3466 & 4.6069 & 6.8514 & 7.7152 & 4.8178 \\
\hline
\end{tabular}

In the full sample period, results in Table 3 show that $T T$ and $S T$ have a significant long-run equilibrium relationship with expected CPI, stocks and bonds, but not with unexpected CPI. However, the magnitudes of the error correction term are small, and this indicates that $T T$ and $S T$ take a long time to adjust to adjust to innovations in expected CPI and other financial assets, so the economic significance is not great. But when the sample excludes the GFC, AREITs display a correction to the long-run disparity with expected CPI. The large negative magnitude of the second error correction term for $A L L$ and TT (and the ECPI term within the first error correction term for $S T$ ) suggest that departures from the long-term equilibrium adjust quickly, and this means that changes to expected inflationary pressures are reflected speedily into AREIT prices. There are significant long-term adjustment effects for $A L L$ and $S T$ with stocks and bonds but again, the small magnitudes of the error correction terms indicate weak economic significance. The third error correction term for $A L L$ and $T T$ indicate that there is a long-run equilibrium relationship with unexpected CPI.

Table 3: VECM for $A L L, T T$ and $S T$ with expected inflation, unexpected inflation, stocks and bonds. The vector error correction models were estimated based on the number of cointegrating vectors detected and presented in Table 2 . $* * *$, ** and $*$ denote statistical significance at the $1 \%, 5 \%$ and $10 \%$ levels.

\begin{tabular}{|c|c|c|c|c|c|c|}
\hline & \multicolumn{3}{|c|}{ Includes GFC $(n=123)$} & \multicolumn{3}{|c|}{ Excludes GFC $(n=112)$} \\
\hline & $d R E I T_{t}=d A L L_{t}$ & $d R E I T_{t}=d T T_{t}$ & $d R E I T_{t}=d S T_{t}$ & $d R E I T_{t}=d A L L_{t}$ & $d R E I T_{t}=d T T_{t}$ & $d R E I T_{t}=d S T_{t}$ \\
\hline ECl & 0.0006 & $0.02195 * * *$ & $0.0119 * * *$ & $-0.0596 * *$ & -0.0366 & $0.0343 * *$ \\
\hline$E C 2$ & & -2.7319 & 0.5160 & $-14.6250 * *$ & $-12.2754 *$ & 3.0501 \\
\hline EC3 & & & & $2.2990 * *$ & $2.3489 *$ & \\
\hline$d R E I T(-1)$ & -0.1505 & -0.1206 & 0.0585 & 0.2037 & 0.1909 & 0.1515 \\
\hline$d R E I T(-2)$ & -0.1106 & 0.0006 & -0.0168 & 0.1541 & $0.3107^{*}$ & 0.0942 \\
\hline$d U C P I(-1)$ & -9.6080 & 18.7539 & 21.8464 & 21.4251 & 25.9771 & 21.5143 \\
\hline$d U C P I(-2)$ & $65.4910^{*}$ & $74.0638 *$ & $82.7434 * * *$ & 28.3997 & $59.1177 *$ & $49.9219 *$ \\
\hline$d E C P I(-1)$ & $-112.8532 * * *$ & $-74.1165^{*}$ & $-102.2795 * * *$ & -14.8792 & -48.4567 & $-58.0977^{*}$ \\
\hline$d E C P I(-2)$ & $89.5295 * *$ & $94.6496 * *$ & $121.0921 * * *$ & 41.7893 & $72.2439 *$ & $79.7220 * * *$ \\
\hline $\operatorname{dSTOCK}(-1)$ & $0.9320 * * *$ & $1.1188^{* * *}$ & $0.3124 *$ & $0.6577 * * *$ & $0.7665^{* * *}$ & 0.1079 \\
\hline dSTOCK (-2) & 0.1811 & -0.0135 & 0.1392 & $0.5165 * *$ & 0.2051 & $0.2914^{*}$ \\
\hline$d B O N D(-1)$ & -10.8915 & -29.7763 & -15.0875 & 6.1578 & -4.7745 & 1.0874 \\
\hline$d B O N D(-2)$ & -23.3456 & $-40.5194 *$ & -16.8098 & -23.6261 & $-35.1653 *$ & -15.4761 \\
\hline Constant & 72.3776 & -37.8411 & -30.3720 & $-65.6257^{*}$ & -63.7161 & -38.9419 \\
\hline
\end{tabular}

The lagged changes of the variables in the VECMs show the short-run effects on AREIT returns. Results from both sample periods including and excluding the GFC indicate that unexpected and expected inflation, as well as stock returns have an impact on AREIT returns. While AREIT returns are largely influenced by inflation, the impact of stock market changes is stronger for traditional than for stapled AREITs. Moreover, changes to bond prices also have a significant impact on traditional AREITs. This was not the case for stapled AREITs, and this provides support that traditional AREITs have both stock and bond like characteristics, whereas stapled AREITs are more like stocks.

Though the results show that AREITs are significantly affected in the long and short-run by inflationary components, expected and unexpected inflation are driven by changes to real economic activity. Moreover, the lack of a significant relationship between AREITs and direct property may be underpinned by the appraisal bias in the measurement of prices. Therefore, the relationships of AREITs with economic variables 
may have meaningful informational content. Industrial production may be used to proxy the demand for real estate and employment indices are used to capture additional primary and secondary demand effects for real estate. The tests are conducted in two stages; first, real activity is measured using INDP and the set of primary factors of demand for real estate are: CON, ERS, MAN and WRT. Increases in activity in these sectors would see an increase in employment numbers, and so represent an immediate increase in demand for real estate to service the increased economic activity. Second, economic activity is measured using INDP and a set of secondary factors for demand for real estate: FIN, GOV, PBS and UTIL. When there are increases in activity in these sectors, they cause complementary spillover effects on the value of real estate. Tables 4 and 5 present the findings of estimations for the long-run error correction terms, and the VECM coefficients.

Table 4: Cointegration and VECM results for AREITs with industrial production and additional primary demand factors for real estate.

One cointegrating vector was detected in each test of $A L L, T T$ and $S T$ in sample periods that include and exclude the GFC. Estimations assumed AREITs were the dependent variable, with $I N D P$ as a factor representing demand for real estate and $C O N, E R S, M A N$ and $W R T$ as additional primary demand factors for real estate. The first part of the table presents the long-run cointegrating coefficients and the second part presents the results of the VECM estimates. ***,** and * denote statistically significant coefficients at the $1 \%, 5 \%$ and $10 \%$ levels respectively.

\begin{tabular}{|c|c|c|c|c|c|c|}
\hline \multirow[b]{2}{*}{ Dependent Var: } & \multicolumn{3}{|c|}{ Includes GFC $(\mathrm{n}=104)$} & \multicolumn{3}{|c|}{ Excludes GFC $(n=93)$} \\
\hline & $A L L$ & $T T$ & $S T$ & $A L L$ & $T T$ & $S T$ \\
\hline$I N D P$ & $-120.05 * * *$ & $-251.10 * * *$ & $-93.36 * * *$ & $35.66^{* * *}$ & $40.85 * * *$ & $26.37 * * *$ \\
\hline$C O N$ & $140.45^{* * *}$ & $315.06 * * *$ & $105.23 * * *$ & $-111.73 * * *$ & $-114.07 * * *$ & $-84.41 * * *$ \\
\hline$E R S$ & $88.77 * * *$ & $195.45 * * *$ & $76.18 * * *$ & $-48.41 * * *$ & $-41.25 * * *$ & $-32.93 * * *$ \\
\hline$M A N$ & -58.85 & -230.39 & -55.17 & $66.56 * *$ & $84.56 * * *$ & $51.75 *$ \\
\hline$W R T$ & $-299.02 * * *$ & $-645.74 * * *$ & $-244.55 * * *$ & $187.72 * * *$ & $164.86^{* * *}$ & $130.79 * * *$ \\
\hline Constant & 29991.86 & 72759.29 & 25339.99 & -14650.40 & -15320.45 & -10219.01 \\
\hline VECM: & $d R E I T_{t}=d A L L_{t}$ & $d R E I T_{t}=d T T_{t}$ & $d R E I T_{t}=d S T_{t}$ & $d R E I T_{t}=d A L L_{t}$ & $d R E I T_{t}=d T T_{t}$ & $d R E I T_{t}=d S T_{t}$ \\
\hline ECMI & $0.0343^{* * *}$ & $0.0203 * * *$ & $0.0203 * *$ & $-0.0518 * *$ & $-0.0521 *$ & 0.0117 \\
\hline$d R E I T(-1)$ & 0.0167 & 0.0379 & 0.1489 & $0.3111^{* *}$ & $0.3586 * * *$ & $0.2935 * *$ \\
\hline $\operatorname{dINDP}(-1)$ & $-5.7634 * *$ & $-4.8496^{*}$ & -1.7021 & -0.9616 & -2.5779 & $3.3704 *$ \\
\hline$d C O N(-1)$ & -6.8549 & $-11.5180 * *$ & 1.2481 & $-7.5186^{* *}$ & $-9.7320 * *$ & 3.6862 \\
\hline$d E R S(-1)$ & 2.8113 & 1.8910 & 1.7439 & -0.4175 & 2.8337 & 2.3366 \\
\hline$d M A N(-1)$ & -0.9769 & 3.5231 & -5.6402 & -0.3981 & 2.0881 & -7.6802 \\
\hline$d W R T(-1)$ & 9.1019 & 9.0561 & 0.7764 & 9.1848 & 6.3459 & -5.0815 \\
\hline Constant & $32.9883 *$ & 33.7914 & 9.0008 & $27.0313 *$ & 23.8261 & 3.1849 \\
\hline
\end{tabular}

The results in Table 4 indicate that in the sample period that includes the GFC, AREITs have a significant long-run relationship with $I N D P, C O N, E R S$ and $W R T$, but not with the manufacturing sector. The error correction term is significant in the VECM and when there are departures from the long-run equilibrium, in the short-term $T T$ adjusts to lagged changes of industrial production and employment in the construction sector. This is not the case for $S T$, and this may be due to stapled AREITs behaving more like general equities, than debt assets and real estate. When the sample period excludes the GFC, the error correction term is only significant for $A L L$ and $T T$, echoing the previous statement. Though lagged changes in the construction sector remain significant in explaining short-term adjustments for $T T$, INDP is significant for only $S T$. In both sample periods, lagged changes in the construction sector have a significant negative impact on the returns of $T T$ and this implies that when construction activity decreases, prices of $T T$ rise.

Table 5: Cointegration and VECM results for AREITs with industrial production and additional secondary demand factors for real estate.

One cointegrating vector was detected in each test of $A L L, T T$ and $S T$ in sample periods that include and exclude the GFC. Estimations assumed AREITs were the dependent variable, with $I N D P$ as a factor representing demand for real estate and FIN, GOV, PBS and $U T I L$ as additional secondary demand factors for real estate.

\begin{tabular}{|c|c|c|c|c|c|c|}
\hline \multirow[b]{2}{*}{ Dependent Var: } & \multicolumn{3}{|c|}{ Includes GFC $(\mathrm{n}=104)$} & \multicolumn{3}{|c|}{ Excludes GFC $(n=93)$} \\
\hline & $A L L$ & $T T$ & $S T$ & $A L L$ & $T T$ & $S T$ \\
\hline$I N D P$ & 6.85 & 14.38 & 5.53 & -3.89 & -3.85 & -2.81 \\
\hline FIN & $140.18 * * *$ & $158.12 * * *$ & $118.28 * * *$ & $135.08 * * *$ & $173.07 * * *$ & $65.82 * * *$ \\
\hline$G O V$ & $91.25 * * *$ & $115.06^{* * *}$ & $87.43 * * *$ & $92.59 * * *$ & $130.45^{* * *}$ & $32.92 * *$ \\
\hline$P B S$ & $-99.27 * * *$ & $-120.19 * * *$ & $-87.11 * * *$ & $-89.47 * * *$ & $-113.09 * * *$ & $-44.87 * * *$ \\
\hline UTIL & $-119.55^{* * *}$ & $-128.32 * * *$ & $-88.48 * * *$ & $-126.20 * * *$ & $-160.25 * * *$ & $-60.54 * * *$ \\
\hline Constant & -4344.93 & -6767.09 & -5375.17 & -2823.39 & -5340.48 & 122.32 \\
\hline VECM: & $d R E I T_{t}=d A L L_{t}$ & $d R E I T_{t}=d T T_{t}$ & $d R E I T_{t}=d S T_{t}$ & $d R E I T_{t}=d A L L_{t}$ & $d R E I T_{t}=d T T_{t}$ & $d R E I T_{t}=d S T_{t}$ \\
\hline ECM1 & $-0.0301 * *$ & $-0.0293 * *$ & -0.0120 & $-0.0307 * *$ & $-0.0246^{*}$ & -0.0113 \\
\hline$d R E I T(-1)$ & $0.2519 * *$ & $0.2171 * *$ & $0.3718 * * *$ & $0.3207 * *$ & $0.3303 * * *$ & $0.2997 * *$ \\
\hline$d I N D P(-1)$ & $-7.1217 * * *$ & $-7.3165 * *$ & -1.7146 & -1.5917 & -3.5765 & 2.7047 \\
\hline$d F I N(-1)$ & -0.5926 & 0.7515 & 0.4343 & 0.6065 & 0.5471 & 1.6792 \\
\hline$d G O V(-1)$ & 1.9054 & 0.6309 & 3.5071 & 2.8174 & 7.0846 & $5.6710^{*}$ \\
\hline$d P B S(-1)$ & $-4.1649 * *$ & -2.3842 & $-3.0344 * *$ & -2.1851 & 0.0855 & -0.9587 \\
\hline$d U T I L(-1)$ & 7.4565 & 3.9457 & $9.9438 * *$ & -2.0478 & -3.9097 & 3.7606 \\
\hline Constant & $33.4733 *$ & 28.6508 & 11.1686 & 24.2261 & 16.1203 & 5.2333 \\
\hline
\end{tabular}


Secondary demand factors of real estate are assessed in Table 5. The long-run coefficients and error correction terms in the VECM indicate that there is an equilibrium relationship between $A L L$ and $T T$ with FIN, GOV, PBS and UTIL. When the sample period includes the GFC, TT adjusts in the short term to lagged changes in $I N D P$ but this is not the case when the sample period excludes the GFC. $S T$ adjusts in the short term to lagged changes in $P B S$ and $U T I L$ in the sample period including the GFC, but only towards $G O V$ in the sample period excluding the GFC.

\section{CONCLUSION}

In this paper, we examined the relationships between traditional and stapled AREITs with expected and unexpected prices of direct property investments and find that there is no long-run relationship between AREITs and expected capital growth of retail properties and unexpected capital growth of industrial properties. Stapled AREITs do not exhibit any relationship with unexpected capital growth of office properties. These results only apply when the sample period excludes the GFC. The significance of the error correction term when direct property was assumed as the dependent variable provides support that AREIT prices are significant in explaining expected and unexpected capital growth of direct properties. We also find that in the long-run, AREITs are good hedges against expected inflation, but only stapled AREITs can hedge against unexpected inflation. The results of the VECM also indicate that traditional AREITs exhibit short-run adjustments to both stock and bond market factors, whereas stapled AREITs only adjust to stocks. When assessed against a set of macroeconomic variables representing primary demand factors for real estate, we find that traditional AREITs display a significant relationship with industrial production and employment in the construction sector. In the set of secondary demand factors for real estate, we find a persistent long-run relationship for traditional AREITs in periods including and excluding the GFC. Overall, our findings suggest that stapled AREITs do not display a long-run relationship with macroeconomic factors that drive real estate prices, providing further support that stapled AREITs are more like stocks and are poor substitutes for direct property investments.

\section{REFERENCES}

Chan, K.C., Hendershott, P.H. and Sanders A.B. (1990), Risk and return on real estate: Evidence from equity REITs. Real Estate Economics, 18(4), 431 - 452.

Clayton, J., and MacKinnon, G. (2001), The time-varying nature of the link between REIT, real estate and financial asset returns. Journal of Real Estate Portfolio Management, 7(1), 43 - 54.

Glascock, J.L., Lu, C., and So, R. (2000), Further Evidence on the Integration of REIT, Bonds and Stock Returns. Journal of Real Estate Finance and Economics, 20(2), 177 - 194.

Gyourko, J. and Keim D.B. (1992), What does the stock market tell us about real estate returns? Journal of the American Real Estate and Urban Economics Association, 20(3), 457 - 485.

Johansen, S. (1988), Statistical analysis of cointegration vectors. Journal of Economics Dynamics and Control, 12, $231-254$.

Johansen, S. (1991), Estimation and hypothesis testing of cointegration vectors in Gaussian vector autoregressive models. Econometrica, 59(6), 1551 - 1580.

Karolyi, G.A. and Sanders, A.B. (1998), The variation of economic risk premiums in real estate returns. Journal of Real Estate Finance and Economics, 17(3), 245 - 262.

Liang, Y. and McIntosh, W. (1998), Employment growth and real estate return: Are they linked? Journal of Real Estate Finance and Economics, 14(3), 283 - 307.

Ling, D.C., and Naranjo, A. (1999), The Integration of Commercial Real Estate Markets and Stock Markets. Real Estate Economics, 27(3), 483 - 515.

Liu, C.H., Hartzell, D.J., and Hoesli, M.E. (1997), International evidence on Real Estate Securities as an Inflation Hedge. Journal of American Real Estate and Urban Economics Association, 5(2), 193 - 221.

Myer, N., and Webb, J. (1993), Return Properties of Equity REITs, Common Stocks and Commercial Real Estate: A Comparison. Journal of Real Estate Research, 8, 87- 106.

Newell, G., and Peng, H.W. (2009), The Impact of the Global Financial Crisis on A-REITs. Pacific Rim Property Research Journal, 15(4), 453 - 470.

Newell, G., and Tan, Y.K. (2005), The Changing Risk Profile of Listed Property Trusts. Paper presented at The Pacific Rim Real Estate Society Conference, Melbourne, 23 - 27 January 2005.

West, T. and Worthington, A.C. (2006), Macroeconomic risk factors in Australian commercial real estate, listed property trust and property sector stock returns: A comparative analysis using GARCH-M. Journal of Financial Management of Property and Construction, 11(2), 21 - 31. 